\title{
PENGARUH PENGELOLAAN ARSIP TERHADAP EFISIENSI KERJA DI SUB BAGIAN KEPEGAWAIAN RSUD Dr. SOEDIRMAN KEBUMEN
}

\author{
Uswatun Khasanah dan Sutriono \\ Politeknik Dharma Patria Kebumen \\ Khasanah_2211@yahoo.com
}

\begin{abstract}
Archives are documents (original text) that are made and received by States Institution and Government/Private/Individual Departrment in various forms, both single and collective for government activity and nation life. The purpose of the researh is to know how the effect of management of the archives of work efficiency in Sub-section of staffing RSUD Dr. Soedirman Kebumen. The problems which are studied including: (1) how the management of archives in Sub-section of staffing RSUD Dr. Soedirman Kebumen, (2) the effect of management archives of work efficiency in Sub-section of staffing RSUDDr. Soedirman Kebumen. This research was conducted at the RSUD Dr. Soedirman Kebumen located in the Lingkar Selatan Muktisari street Kebumen by taking the subject of research, officials or employees in the sub-section of staffing. This type of research is descriptive method and regression and correlation method. While data collection method used is monitoring (observation), interviews, and questionnaires. From the results of this research, it is known that there is strong positive relationship between the management of the archive of work efficiency in sub-section of staffing RSUD Dr. Soedirman Kebumen. It is evident from the pearson correlation test results earned value 0,910 and calculation of questionnaires that States $82,8 \%$ work efficiency in sub-section of staffing RSUD Dr. Soedirman Kebumen influence by management of archive while 17,2 \% influence by another factor. The problem of management of the archive is limitedness of officer to handle the archive. Thus, the need for special officer in managing the archive.
\end{abstract}

Keyword :the management of the archive, work eficiency, Analysis Ofregression and correlation

\section{A. PENDAHULUAN}

Setiap instansi baik instansi pemerintah maupun swasta memiliki dokumen-dokumen penting yang harus tetap disimpan dan dijaga dengan baik. Dokumen-dokumen tersebut juga sering dinamakan dengan istilah arsip atau file. Arsip adalah kumpulan warkat yang disimpan secara sistematis karena mempunyai kegunaan agar setiap kali diperlukan dapat secara cepat ditemukan kembali. Sedangkan warkat merupakan catatan tertulis, gambar atau rekaman yang memuat sesuatu hal atau peristiwa yang digunakan orang sebagai pengingat (alat bantu ingatan). Oleh karena itu arsip perlu dikelola dengan tepat agar dapat membantu dalam mencapai tujuan secara efisien.

Penataan arsip merupakan kegiatan mengatur dan menyusun arsip sehingga membentuk berkas sesuai dengan tipe dan kegunaan arsip bagi kepentingan pakerjaan. Prinsip utama dalam penataan arsip adalah arsip harus diberkaskan menurut kesamaan urutan (dosir), kesamaan masalah (rubrik), dan kesamaan jenis (seri), sesuai dengan kebutuhannya. Penataan arsip mencakup tiga unsur pokok, yaitu penyimpanan, penempatan, dan penemuankembali.

Mengingat peran arsip sangat penting, maka sebaiknya arsip dikelola dengan baik dan benar sehingga dapat membantu dalam penentuan kebijakan dan pedoman kerja guna pencapaian visi misi sebuah instansi. Arsip menjadi media penunjang yang mempunyai peranan penting dalam menunjang kinerja pegawai.

Salah satu instansi yang memerlukan arsip kepegawaian adalah Rumah Sakit Umum Daerah Dr. Soedirman Kebumen yang menyelenggarakan pelayanan kesehatan di bawah Pemerintah Daerah Kabupaten Kebumen. Arsip kepegawaian secara lengkap meliputi data pribadi, data karir (riwayat jabatan, kepangkatan), data pendidikan (formal dan informal), data remunerasi (gaji, tunjangan, penggantian biaya, dan lain-lain), data performansi kerja (absensi, penilaian, sanksi, dan lain-lain). Untuk meningkatkan kinerja pegawai, ketersediaan informasi yang cepat makin penting dalam mendukung upaya peningkatkan pelayananinformasi 
kepegawaian pada sub bagian kepegawaian RSUD Dr. Soedirman Kebumen. Oleh karena itu, pengelolaan arsip harus dilakukan dengan sebaik mungkin. Warkat harus dikelompokan berdasarkan kriteria masing-masing yang dibutuhkan. Agar pengarsipan dapat efektif, maka arsip harus di cek dan diperbarui secara berkala. Selain itu, dalam pengumpulan arsip sebaiknya diprioritaskan warkat yang dibutuhkan dalam kepegawaian guna menghindari pemborosan, baik pemborosan kertas, ordner maupun tempat arsip.

Bertambahnya arsip secara terus-menerus tanpa diikuti dengan tata kerja dan peralatan kearsiapan serta tenaga ahli dalam bidang kearsipan, menimbulkan masalah tersendiri. Selain itu, belum adanya petugas khusus dalam bidang kearsipan yang ditempatkan di bagian arsip kepegawaian juga menjadi kendala. Selama ini, petugas yang mengelola arsip pegawai merupakan pegawai bagian kepegawaian.

\section{B. METODE}

1. Metode Penelitian

Metode penelitian yang digunakan dalam penelitian ini adalah metode penelitian deskriptif kuantitatif korelasional, yaitu metode yang digunakan untuk menggambarkan atau menjelaskan masalah dengan cara mencari, mengumpulkan serta mempelajari data dari suatu populasi atau sampel tertentu. Dengan penelitian data bersifat kuantitatif atau statistik, kemudian disusun secara sistematis untuk diambil kesimpulan. Pendekatan kuantitatif dalam penelitian ini digunakan untuk mengetahui hubungan pengelolaan arsip pegawai terhadap efektifitas dan efisiensi kerja.

2. Populasi dan Sampel Penelitian

Menurut Jonathan Sarwo (2006:111), "Populasi merupakan seperangkat unit analisis lengkap yang sedang diteliti. Sedangkan sampel adalah subbagian dari seperangkat elemen yang dipilih untuk dipelajari.

Sugiyono (2012:86) mengungkapkan :

Jumlah sampel yang diambil sama dengan jumlah populasi. Semakin besar jumlah sampel mendekati populasi, maka peluang kesalahan generalisasi semakin kecil. Sebaliknya, semakin kecil jumlah sampel menjauhi populasi, maka semakin besar kesalahan generalisasi (diberlakukan umum).

Dalam penelitian ini, sampel yang digunakan sebanyak 8 responden dari 10 orang yang merupakan populasi pegawai Sub Bagian Kepegawaian RSUD dr. Soedirman Kebumen.

3. Teknik Pengumpulan Data

Adapun teknik pengambilan data yang dilakukan pada Praktek Kerja Lapanganadalah sebagai berikut:

a. Observasi

Teknik observasi merupakan segala usaha yang dilakukan oleh peneliti untuk menghimpun informasi yang relevan dengan topik atau masalah yang akan diteliti

b. Wawancara

Teknik wawancara merupakan suatu bentuk pengumpulan data yang dilakukan oleh penulis dengan cara mengadakan wawancara maupun diskusi dengan instruktur pada waktu melaksanakan kerja lapangan untuk menggali lebih jauh atas permasalahan yang dibahas.

c. Kuisioner

Mengajukan pernyataan tertulis yang dibagikan kepada responden yaitu beberapa pegawai di Sub Bagian Kepegawaian RSUD Dr. Soedirman Kebumen. Kuesioner dilakukan dengan tujuan mendapatkan informasi yang relevan dengan tujuan survei agar diperoleh tingkat keakuratan yang tinggi.

4. Teknik Analisis Data

a. Regresi

Regresi adalah suatu metode statistika yang berguna untuk memeriksa atau memodelkan hubungan diantara variabel-variabel. Variabel-variabel tersebut dengan menggunakan analisis regresi dapat melihat adanya pengaruh suatu karakteristik terhadap data lain. Dengan kata lain jika kita mempunyai dua atau lebih variabel maka kita dapat mencari suatu cara bagaimana variabel-variabel itu berhubungan. Dan hubungan tersebut secara matematika dinyatakan sebagai hubungan fungsional antara variabel-variabel. 
Jadi prinsip dasar yang harus dipenuhi dalam membangun suatu persamaan regresi adalah bahwa antara suatu variabel tidak bebas (dependent variabel) dengan variabel-variabel bebas (independent variabel) lainnya memiliki sifat hubungan sebab akibat (hubungan kausal), baik didasarkan pada teori, hasil penelitian sebelumnya, maupun yang didasarkan pada penjelasan logis tertentu.

Regresi linier sederhana digunakan untuk memperkirakan hubungan antara dua variabel di mana hanya terdapat satu variabel bebas/peubah bebas $\mathrm{X}$ dan satu variabel tak bebas $\mathrm{Y}$. Dalam bentuk persamaan umum, model regresi sederhana adalah :

$$
\mathbf{Y}=\mathbf{a}+\mathbf{b X}
$$

dimana:

$\mathrm{Y}$ : adalah variabel terikat/tak bebas (dependent)

$\mathrm{X}$ : adalah variabel bebas (independent)

a : adalah penduga bagi intercept

$\mathrm{b}$ : adalah penduga bagi koefisien regresi

b. Korelasi

Korelasi adalah istilah statistik yang menyatakan derajat hubungan linier antara dua variabel atau lebih. Korelasi ditemukan oleh Karl Pearson pada awal tahun 1900 sehingga korelasi sering disebut Korelasi Pearson Product Moment (PPM). Produk korelasi atau pengukuran digunakan untuk melihat kuat lemahnya korelasi disebut koefisien korelasi yang sering disimbolkan dengan $\mathrm{r}$ atau $\mathrm{R}$ (penggunaan $\mathrm{r}$ biasanya pada korelasi parsial sedangkan $\mathrm{R}$ digunakan pada korelasi berganda). Untuk mendapatkan nilai koefisien korelasi antara variabel tak bebas $\mathrm{Y}$ dengan variabel bebas maka dapat digunakan rumus sebagai berikut :

$$
\mathrm{r}_{\mathrm{xy}}=\frac{\mathrm{n} \Sigma \mathrm{X}_{\mathrm{i}} \mathrm{Y}_{\mathrm{i}}-\left(\Sigma \mathrm{X}_{\mathrm{i}}\right)\left(\Sigma \mathrm{Y}_{\mathrm{i}}\right)}{\sqrt{\left\{\mathrm{n} \Sigma \mathrm{X}_{\mathrm{i}}^{2}-\left(\Sigma \mathrm{X}_{\mathrm{i}}\right)^{2}\right\}\left\{\mathrm{n} \Sigma \mathrm{Y}_{\mathrm{i}}^{2}-\left(\Sigma \mathrm{Y}_{\mathrm{i}}\right)^{2}\right\}}}
$$

Koefisien korelasi memiliki nilai antara -1 hingga +1 . Sifat nilai koefisien korelasi adalah plus (+) atau minus (-) yang menunjukan arah korelasi. Sifat korelasi akan menentukan arah dari korelasi. Keeratan korelasi dapat dikelompokkan sebagai berikut:

Tabel 2.1 Interpretasi dari nilai $R$

Sumber : Algifari, 1997

\begin{tabular}{|c|c|}
\hline $\mathrm{R}$ & Interpretasi \\
\hline 0 & Tidak ada korelasi \\
\hline $0,01-0,20$ & Sangat Lemah \\
\hline $0,21-0,40$ & Lemah \\
\hline $0,41-0,70$ & Kuat \\
\hline $0,71-0,90$ & Sangat Kuat \\
\hline $0,91-0,99$ & Sangat Kuat Sekali \\
\hline 1 & Sempurna \\
\hline
\end{tabular}

c. Koefisien Determinasi $\left(\mathrm{r}^{2}\right)$

Koefisien determinasi yang disimbolkan dengan $\mathrm{r}^{2}$ bertujuan untuk mengetahui seberapa besar kemampuan variabel independent menjelaskan variabel dependent. Nilai $\mathrm{r}^{2}$ dikatakan baik jika berada di atas 0,5 karena nilai $\mathrm{r}^{2}$ berkisar antara 0 dan 1 . Pada umumnya model regresi linier berganda dapat dikatakan layak dipakai untuk penelitian, karena sebagian besar variabel dependen dijelaskan oleh variabel independen yang digunakan dalam model.

\section{HASIL DAN PEMBAHASAN}

Dalam perkembangan dan kemajuan manajemen dokumentasi sekarang ini hampir dapat dipastikan bahwa segala sesuatu tergantung kepada warkat/dokumen. Pengelolaan arsip berfungsi sebagai inti dari sebuah kegiatan setiap organisasi dan berguna membantu bagi 
pemimpin untuk menentukan kebijaksanaan. Pengelolaan arsip bertujuan untuk memudahkan dalam penyimpanan arsip dan penemuan kembali arsip. Adapun indikator dalam pengelolaan arsip meliputi sarana dan prasarana serta penyelenggaraan arsip..

Pengelolaan arsip yang dilaksanakan pada Sub Bagian Kepegawaian RSUD Dr.Soedirman Kebumen yaitu pola yang digunakan adalah pola "Gabungan". Pola penyimpanan arsip secara gabungan yaitu menggunakan kombinasi dari dua pola penyimpanan antara sentralisasi dan desentralisasi. Artinya semua arsip disimpan pada pusat arsip bagian kepegawaian dan juga salinannya disimpan pada setiap unit bagian masing-masing. Pola penyimpanan ini dipilih karena RSUD Dr. Soedirman merupakan instansi yang mempunyai volume pegawai yang cukup besar dengan berbagai macambidang kerja. Dengan demikian masing-masing pegawai bisa menyimpan dan menggunakan salinan dari arsip dengan mudah dan cepat.

Sistem penyimpanan arsip atau warkat di Sub Bagian Kepegawaian RSUD Dr. Soedirman menggunakan 2 sistem. Arsip disusun menggunakan sistem pokok soal terlebih dahulu berdasarkan statusnya seperti PNS, BLUD maupun THL. Selain itu, juga dipisahkan berdasarkan bidang kerjanya seperti dokter, perawat, bidan, staff dll. Setelah dipisahkan berdasarkan sistem pokok soal, arsip disusun berdasarkan sistem abjad. Arsip disimpan dalam masing masing ordner menurut abjad dari nama-nama pegawai RSUD Dr. Soedirman Kebumen yang tertera dalam tiap-tiap map atau ordner.Masing masing ordner pegawai berisi arsip yang berkaitan dengan urusan kepegawaian seperti daftar riwayat hidup, surat tugas, surat kenaikan pangkat, surat kenaikangaji berkala, dll.

Faktor kearsipan pada umumnya merupakan faktor penunjang penyelenggaraan tata laksana kantor yang berujung padapelayanan yang efektif dan efisien. Untuk mencapai hal tersebut, dibutuhkan pengelolaan yang baik terhadap arsip itu sendiri.Indikator dalam menentukan efisiensi kerja meliputi kualitas, kuantitas dan waktu. Sebagai hasil penelitian yang dilakukan oleh peneliti, pada umumnya kinerja pegawai di Sub Bagian Kepegawaian RSUD Dr. Soedirman Kebumen sudah baik.

Berdasarkan hasil perhitungan uji validitas, menunjukan bahwa $\mathrm{r}_{\text {hitunglebih besar dari }}$ $\mathrm{r}_{\text {tabel }}$ yang bernilai 0,707 pada signifikan 5\%.Sehingga dapat dikatakan bahwa item angket Variabel Pengelolaan Arsip (X) dan Variabel Efisiensi Kerja (Y) valid digunakan.

Analisis regresi bermaksud menguji hubungan fungsional yangterjadi antara satu variabel dependen dengan satu atau lebih variableindependen. Setelah semua variabel dimasukkan, penyelesaian model regresilinier dilakukan dengan bantuan Program SPSS 16.0 dan perhitungan selengkapnya dapat dilihat pada lampiran. Adapun hasilnya adalah sebagai berikut :

\begin{tabular}{|c|c|c|c|c|}
\hline \multirow[b]{2}{*}{ Model } & \multicolumn{2}{|c|}{ Unstandardized Coefficients } & \multirow{2}{*}{\begin{tabular}{|l} 
Standardized \\
Coefficients
\end{tabular}} & \multirow[b]{2}{*}{$\mathrm{T}$} \\
\hline & B & Std. Error & & \\
\hline 1(Constant) & -8.167 & 7.199 & & -1.135 \\
\hline $\mathrm{X}$ & 1.211 & .225 & .910 & 5.378 \\
\hline
\end{tabular}

a. Dependent Variable: Y

Dari hasil analisis di atas, maka model persamaan regresi linier yang diperoleh adalah $: Y=-8,167+1,211(\mathrm{X})$. Artinya jika skor pengelolaan arsip meningkat,maka skor efisiensi kerja juga akanmeningkat. Sebaliknya jika skor pengelolaan arsip menurun, maka skor efisiensi kerja juga akan menurun.

Analisis korelasi merupakan analisis yang digunakan untuk mengetahui hubungan antara variabel $\mathrm{X}$ dan variabel $\mathrm{Y}$ yaitu dengan menggunakan suatu bilangan yang disebut koefisien korelasi (r). Berdasarkan hasil olah data dengan SPSS diketahui sebagai berikut : 


\section{Correlations}

\begin{tabular}{|l|r|r|}
\hline & $\mathrm{X}$ & $\mathrm{Y}$ \\
\hline Pearson Correlation & 1 & $.910^{* * *}$ \\
Sig. (2-tailed) & & .002 \\
$\mathrm{~N}$ & 8 & 8 \\
\hline Pearson Correlation & $.910^{* *}$ & 1 \\
Sig. (2-tailed) & .002 & \\
$\mathrm{~N}$ & 8 & 8 \\
\hline
\end{tabular}

**. Correlation is significant at the 0.01 level (2-tailed).

\section{Sumber : Output SPSS}

Dari output diatas diketahui koefisien korelasi sebesar 0,910 ini berarti terdapat hubungan yang sangat kuat antara pengelolaan arsip (X) dengan efisiensi kerja (Y).

Analisis determinasi digunakan untuk mengetahui seberapa besar prosentase pengaruh yang sudah di uji memakai uji korelasi. Nilai koefisien determinasi $\left(\mathrm{R}^{2}\right)$ menunjukan prosentase pengaruh variabel $(\mathrm{X})$ terhadap variabel $(\mathrm{Y})$.

Tabel. 3.11. Koefisien Determinasi

\section{Model Summary}

\begin{tabular}{l|c|c|l|l|}
\hline Model & $\mathrm{R}$ & $\begin{array}{c}\mathrm{R} \\
\text { Square }\end{array}$ & $\begin{array}{c}\text { Adjusted R } \\
\text { Square }\end{array}$ & $\begin{array}{c}\text { Std. Error of } \\
\text { the Estimate }\end{array}$ \\
\hline 1 & $.910^{\mathrm{a}}$ & .828 & .800 & 3.003 \\
\hline
\end{tabular}
a. Predictors: (Constant), X
Sumber: Output SPSS

Dari tabel tersebut diketahui nilai koefisien determinasi yang merupakan pengkuadratan dari R adalah sebesar 0,828. Artinya efisiensi kerja (Y) dipengaruhi oleh pengelolaan arsip (X) sebesar 82,8\% sedangkan 17,2\% dipengaruhi oleh faktor lain.

Pengelolaan arsip di Sub Bagian Kepegawaian RSUD Dr. Soedirman Kebumen tergolong sudah baik, meskipun masih dilakukan dengan sederhana. Namun masih terdapat beberapapetunjuk guide, folder maupun laci yang rusak dan belum terpasang. Selain itu, arsip belum tertata rapi karena terdapat salinan arsip yang lebih dalam ordner. Beberapa arsip juga belum ditempatkan sesuai ordner masing-masing.Hal itu disebabkan keterbatasan petugas yang menangani arsip dengan jumlah banyak.

Upaya yang dilakukan dalam temu kembali arsip dengan cepat dan tepat yaitu diantaranya petugas terlebih dahuluperlu memahami perlengkapan dalam pengelolaan arsip seperti guide (kertas tebal), folder (ordner) dan laci (lemari arsip). Perlengkapan tersebut dipasang petunjuk seperti jenis arsip pada guide, nama pegawai pada folder dan status/bidang kerja pada laci. Petunjuk yang rusak atau belum terpasang segera diganti guna memudahkan temu kembali arsip. Arsip pegawai harus dipisahkan satu per satu dan dimasukan ke dalam setiap ordner pegawai yang bersangkutan. Arsip tersebut dikelompokan dengan cara diberi pembatas dengan kertas tebal sebagai petunjuk guide berdasarkan jenis arsip.

Perlu adanya penyusutan terhadap arsip yang salinannya terlalu banyak. Sebaiknya arsip yang disimpan sebanyak 1 atau 2 lembar saja. Dengan demikian, arsip yang tersimpan merupakan arsip yang mempunyai informasi yang benar-benar berguna dan bermutu.

Gunameningkatkan pengelolaan arsip pegawai, perlu adanya petugas yang khusus dalam mengelola arsip. Meskipun tidak adanya petugas khusus yang mengelola arsip, perlu adanya pelatihan terhadap pegawai di Sub Bagian Kepegawaian tentang pengelolaan arsip yang baik sesuai dengan aturan kearsipan yang berlaku. Selain menambah pengetahuan tentang kearsipan, juga membantu dalam temu kembali arsip dengan cepat dan tepat. Dengan 
demikian, arsip dapat dikelola secara maksimal dan dapatmeningkatkan efisiensi kerja di Sub Bagian Kepegawaian RSUD Dr.Soedirman Kebumen.

\section{PENUTUP}

\section{Kesimpulan}

1. Berdasarkan hasil kuesioner variabel $X$ diperoleh hasil 50\% responden masuk dalam kategori baik dan 50\% masuk dalam kategori sedang sehingga pengelolaan arsip di Sub Bagian Kepegawaian RSUD Dr.Soedirman Kebumen tergolong baik.

2. Berdasarkan hasil kuesioner variabel $Y$ diperoleh hasil 37,5\% responden masuk dalam kategori baik dan 62,5\% masuk dalam kategori sedang sehingga efisiensi kerja di Sub Bagian Kepegawaian RSUD Dr. Soedirman Kebumen tergolong baik.

3. Dari hasil uji korelasi pearson diperoleh nilai sebesar 0,910 artinya adanya hubungan yang kuat positif antara pengelolaan arsip terhadap efisiensi kerja pada Sub Bagian Kepegawaian RSUD Dr. Soedirman Kebumen.

4. Efisiensi kerja di Sub Bagian Kepegawaian RSUD Dr. Soedirman Kebumen dipengaruhi oleh pengelolaan arsip sebesar 82,8\% dan sisanya 17,2\% dipengaruhi oleh faktor lain.

5. Masalah utama dalam pengelolaan arsip di Sub Bagian Kepegawaian RSUD Dr. Soedirman Kebumen adalah keterbatasan petugas khusus yang memahami prosedur pengelolaan arsip sesuai dengan aturan kearsipan yang berlaku.

6. Solusi yang dilakukan adalah pengadaan petugas khusus yang memahami prosedur pengelolaan arsip dan mampu mengelola arsip dengan baik dan maksimal. Selain itu, adanya pelatihan kepada petugas dalam mengelola arsip yang baik dan benar sesuai aturan kearsipan yang berlaku

\section{Saran}

1. Pengelolaan arsip sebaiknya dilakukan secara periodik atau rutin terutama dalam penyusutan arsip sehingga arsip dapat tertata dengan rapi.

2. Perlu adanya pengembangan dengan cara pengelolaan arsip berbasis IT (informasi teknologi) untuk mempermudah penemuan kembali arsip serta mengantisipasi kerusakan arsip

\section{E. DAFTAR PUSTAKA}

Amsyah, Zulkifli (2003), Manajemen Kearsipan, PT Gramedia Pustaka Utama, Jakarta.

Badri Munir Sukoco. 2007. Manajemen Administrasi Perkantoran Modern. Erlangga. Jakarta.

Mintorogo, Sedamaryanti, Dra, (1992) Dasar-dasar Pengetahuan Tentang manajemen Perkantoran, Ilham Jaya, Bandung.

The Liang Gie. 2000. Administrasi Perkantoran Modern. Liberty. Yogyakarta 